\section{GPS WITH ENHANCED SURGICAL SKILLS: A QUESTIONABLE SOLUTION FOR REMOTE SURGICAL SERVICES}

I respond to arguments by Drs. Vinden and Ott in "GPs with enhanced surgical skills: a questionable solution for remote services" (December 2015). We welcome an evidence-based debate on how to best meet the surgical needs of rural residents in Canada.

The definition of safety in surgery has focused on hospital-based activity related to procedural interventions. ${ }^{1}$ However, quality of care must also include dimensions of acceptability, accessibility, appropriateness, effectiveness and efficiency. ${ }^{2}$ Our patients' definition, similarly, will include impact of travel on finances, loss of supportive relationships, and sense of "community belonging."

After all, location of care is not solely the doctors' decision; patientand family-centred care means that patients and their families (and rural communities) decide where they receive care, informed by data about relative risks and outcomes. "Nothing about us without us." 5

As for the breadth of the skill set proposed, rural population distribution matters. The degree of generalization required to practise in any given setting is inversely proportional to the human resources available. This means that in rural Canada, with its low physician numbers, a broad skill set is necessary and will continue to be practised. "The generalist physician is prepared and willing to reach across the existing gaps in the health care delivery system." The ESS physician crosses one of these gaps.

Any critique around competencybased training must be given within the context of the current curricula redefinition for general surgeons. ${ }^{8}$ The published draft was a scaled-down version, designed to convey the procedural con- tent. The program itself provides foundational content, milestones, etc.

Disparity of time frames in training, although less relevant in a Competence by Design (CBD) framework, is offered as evidence of the inadequacy of the ESS training program. Unlike the vast majority of "rookie" R1 surgical residents, however, ESS residents are not postgraduate yeat (PGY)1s, but are licensable physicians, with at least 2 years of clinical knowledge and skill acquisition, often acquired in lowresource settings where decisionmaking skills have been well tested.

Regarding gastrointestinal endoscopy training, the American Board of Surgery (similar to $\mathrm{CAGS}^{9}$ ) reiterates the importance of rural care and of deemphasizing specialty designation, stating that "patients will be best served by establishing validated quality indicators for proficiency, (...)using these more objective standards." 10

How does centralization of care affect care delivery? Malik and colleagues ${ }^{11}$ argue that a massive shift toward geographically centralized care would imperil a host of other services, and thus argue strongly against such centralization (despite demonstrably worse outcomes). Safety and quality must have a broader context than hospital statistics.

Finally, will the current "surplus" of surgical human resources solve rural surgical issues? New general surgeons who are prepared for rural practice are rare, but even those who are will bring with them substantial resource requirements. ${ }^{12}$ Rural places would welcome such an influx, but for now will continue to provide the best possible care with the available resources.

\section{Randall Friesen, MD}

From the Department of Surgery, University of Saskatchewan, Saskatoon, Sask.

DOI: $10.1503 /$ cjs.001616

\section{References}

1. Warnock, GL. Of surgeons and safety checklists. Can f Surg 2010;53:364-6.

2. Alberta Quality Matrix For Health. Health Quality Council of Alberta, 2005. Available: http://hqca.ca/about/how-we-work /the-alberta-quality-matrix-for-health-1/ (accessed 2016 May 13).

3. Humber N, Dickinson P. Rural patients' experiences accessing surgery in British Columbia. Can 7 Surg 2010;53:373-8.

4. First Nations, Inuit, Métis Health: core competencies. Curriculum framework for continuing medical education. 2009, The Indigenous Physicians Association of Canada-RCPSC Advisory Committee.

5. Nothing about us without us: disability oppression and empowerment. James I. Charlton, University of California Press, 2000.

6. Geographic distribution of physicians in Canada. Beyond how many and where. 2005, CIHI. Available: https://secure.cihi.ca /free_products/Geographic_Distribution_of _Physicians_FINAL_e.pdf (accessed 2016 May 13).

7. Royal College of Physicians and Surgeons of Canada. Generalism: achieving a balance with specialization. Jan. 2011. Available: www.royalcollege.ca/portal/page/portal/rc /common/documents/educational_initiatives /generalism.pdf (accessed 2016 May 13).

8. Royal College of Physicians and Surgeons of Canada. The future of general surgery. Evolving to meet a changing practice. Final report of the Task Force on General Surgery, Feb. 2014. Available: www.royal college.ca/portal/page/portal/rc/common /documents/educational_initiatives/future _of_general_surgery_report_e.pdf (accessed 2016 May 13).

9. Reid S, George R, Warnock GL, et al. Canadian Association of General Surgeons statement on endoscopy. Can 7 Surg 2011; 54:295.

10. ABS Statement on GI Endoscopy. Available: www.absurgery.org/default.jsp?newsgi response (accessed 2016 May 13).

11. Malik A, Bell CM, Stukel TA, et al. Recurrence of inguinal hernias repaired in a large hernia surgical specialty hospital and general hospitals in Ontario, Canada. Can 7 Surg 2016;59:19-25.

12. Canadian Association of General Surgeons. Draft position on resources for general surgeons. Available: www.cags-accg.ca/docs /resourcesforgensurgeons.pdf (accessed 2016 May 13). 